\title{
I Landed a U.F.O. on Main Street: An Autoethnography of the Founding of an Arts Education Organization in Appalachian Kentucky
}

\author{
Elise L. Kieffer PhD \\ Murray State University, ekieffer@murraystate.edu
}

Follow this and additional works at: https://digitalcommons.murraystate.edu/faculty

Part of the Appalachian Studies Commons, Art Education Commons, Arts Management Commons, and the Nonprofit Administration and Management Commons

\section{Recommended Citation}

Kieffer, Elise. 2019. "I Landed a U.F.O. on Main Street: An Autoethnography of the Founding of an Arts Education Organization in Appalachian Kentucky." The International Journal of Social, Political and Community Agendas in the Arts 14 (1): 1-12. doi:10.18848/2326-9960/CGP/v14i01/1-12.

This Journal Article is brought to you for free and open access by the Faculty Works at Murray State's Digital Commons. It has been accepted for inclusion in Faculty \& Staff Research and Creative Activity by an authorized administrator of Murray State's Digital Commons. For more information, please contact msu.digitalcommons@murraystate.edu. 


\title{
I Landed a U.F.O. on Main Street: An Autoethnography of the Founding of an Arts Education Organization in Appalachian Kentucky
}

\author{
Elise Lael Kieffer
}

\begin{abstract}
The Appalachian region in the southern mid-west has long been the source of stereotyping for dramatic and political affect. Through the course of nine years as a resident in an Appalachian community in southcentral Kentucky, the author experienced life as it is lived by the local people. Through the establishment of an art education organization, the author became entwined with local families and became familiar with the origins of many of those stereotypes. Using autoethnography to interpret her experiences, through the lens of academic research, the author will confront the primary issues that surfaced: the acute designation of outsider status, and the perception of the arts in underexposed communities. The goal of this analysis is to facilitate greater impact by arts organizations into rural populations.
\end{abstract}

Keywords: Arts Education, Organization, Leadership, Autoethnography, Appalachia, Kentucky

\section{Introduction}

The Appalachian region in the southern mid-west of the United States has long been the source of stereotyping for dramatic and political affect. Through the course of nine years as a resident in a community at the foothills of the Appalachian Mountains, I experienced life as it is lived by the local people. Through the establishment of an art education organization, the author became entwined with local families and became familiar with the origins of many of those stereotypes. Using autoethnography to interpret her experiences, the author will confront the primary issues that surfaced: the acute designation of outsider status and the additional perception of the arts in underexposed communities. The goal of this analysis is to facilitate greater impact by arts organizations into rural populations.

In May of 2008, my family relocated from Jersey City, New Jersey into the small town of Burkesville, an Appalachian community situated in south central Kentucky, just north of the Kentucky-Tennessee border. 
Following the birth of our first son, my husband and I cherished the idea of a quiet life away from our jobs in Manhattan, to raise our family in a supportive, close-knit community. We were naïve about the limitations we would face as we tried to build our lives and incorporate our family into the closed ranks of the locality. In addition to the basic struggles we would face as outsiders in a generationally established populace, we further challenged the status quo by having higher levels of education than the average citizen.

The arts education choices for students in the community were limited to a private piano teacher, high school band and high school visual art. There were no dance or theatre opportunities and nothing at all for children below seventh grade. Seeing this lack of artistic opportunities I became excited about my experience as a professional musical theatre performer, and my education in the fine arts as well as non-profit management, as tools to fill the void. I established an arts education organization, Burkesville Academy of Fine Arts (BAFA). I learned that the perception of the arts in the underexposed community was that it was a pastime for young children and little more. The arts are perceived locally as something "other"; something that happens in big cities, but has little to do with them, apart from music at church on Sunday mornings. Because the generations before them were unexposed to the arts there is little value seen in incorporating them into young peoples' lives.

Using autoethnography, I examined my personal experiences through the lens of academic research. I suspected that my experiences were in line with current literature findings, so how might that guide further interaction within rural, isolated communities in the arts?

The specific events addressed in this autoethnography confront two themes that emerged through my review of literature and artifacts. Those themes address my position as an outsider, and the perception of the arts in this rural community. Further research could delve into other experiences, such as navigating the religiously charged atmosphere of the community, unique educational expectations of students within this community, and my status as a woman leading an organization.

\section{Burkesville: The Best Kept Secret in Kentucky (An autoethnography).}

\section{"Yer Not From 'round Here..."}

Outsider status. Outsider status. This single aspect of my time in Burkesville, Kentucky is so overwhelming and all encompassing that it is a challenge to pinpoint one single time when it defined the moment. It permeated everything. I asked my husband if he could think of one event 
or even a couple of events when our status as outsiders was singularly significant to the event, and his answer was, "life."

"Yer not from around here, but "round here but we go ta church on Wednesdays, so yer gonna get a lot of resistance on that" (Parent of a cast member, regarding a rehearsal schedule that included Wednesday afternoons, September, 2013).

"You're not from around here, so I know you think this sounds like a good ideal [sic], but I don't think anyone's gonna send their kids to this camp of yers. We ain't never done that before" (Member of the county fiscal court, April, 2012).

"Maybe if you could find someone from here to promote it for you people would be more likely to participate" (BAFA board member, April 2012).

The irony of the situation was, if any of these statements had been made without the preliminary "You're not from around here...," I would have listened and been inclined to accommodate all of them. I certainly wouldn't want to rehearse on a night that children are vastly unavailable. I am comfortable clarifying the nature of what fine arts camp looks like. However, beginning so many criticisms with the phrase "You're not from around here..." led me to believe that whatever I was offering, whatever I had to say, was automatically irrelevant because, after all, I was not from there. I felt belittled and diminished, as if I were considered less than another person by no fault or failing on my part but, simply because I was new in town.

I have been in the position of outsider before, as a white graduate student attending an HBCU, as a translator on humanitarian aid trips internationally, but in those cases, I felt that I had an opportunity to prove the insiders right or wrong about me. My entrance into their communities came with certain assumptions. I enjoyed surprising people when I turned out not to be quite who they first thought I would be. I took pride in slowly earning their trust and respect. It stretched me and forced me to confront my own notions of myself, and preconceptions of others. I always felt that I came out stronger and kinder for the effort. In this small Kentucky town, I never felt that I could change my situation. My status as other was permanent and indelible.

"Yer not from around here but..." became a joke that my husband and I would swap back and forth in the privacy of our home, having heard these words so many times over the course of our nine years as Cumberland County residents. They loomed as a potential reason for every resistance, obstacle or opposition we faced. Our status as outsiders affected nearly every aspect of life in that rural community, making it hard 
to make friends, because the other people our age had known each other since birth, their parents had gone to school together, their grandparents had been neighbors. How could we possibly compete with that much generationally established, relational history?

From the moment we moved into our home on Main Street we faced suspicion and opposition. We chose our home because it was a beautiful Queen Anne style house, built in 1908 and was perfect for a bed and breakfast, being located right in town, convenient for travelers. A large home, in size and style, we would not have been able to afford it elsewhere. When we moved in we completely renovated the home, focusing primarily on the exterior, landscaping, and décor. While my husband labored to transform the house into something show-worthy, I researched and worked to have the house listed in the National Register of Historic Places by the United States Department of the Interior. This process paid off, and in December of 2009, the property was added to the national register. Prior to the time of the listing, we received many compliments about the progress we were making on the home. Community members shared nostalgic stories about the house and commented that they were glad to see it being restored. When the house was officially recognized as a historic site, the Kentucky Heritage Council promoted the listing in the local paper. Compliments we received just weeks before turned into suspicion and doubt. Questions turned dark, "How does it benefit you for it to be on that list?" Or "Do y'all get anything outta bein' on that list?"

It was shocking, the change in attitude toward our family. We tried very hard to explain that, no, we received no benefit or compensation from the National Register, only the joy of knowing a historic property would be preserved. It was our first glimpse into the suspicion experienced by many outsiders in Appalachia, feeling first-hand their expectation that we would manipulate or take advantage of natural resources for our own benefit. Slowly, as we lived in the community for an additional eight years, these conversations died down.

The challenge of "outsider" status when discussing Appalachian communities is well researched, specifically the concept of educated outsiders (Azano \& Stewart 2015 \& 2016; Vance 2016; Fisher \& Smith 2012; Kahn 2012; Grimes 2016; Haskins and Paisley 2013; Brown \& Swanson 2013). Azano and Stewart (2015 \& 2016) addressed the challenges faced by teachers entering public schools as outsiders, entering the community from other regions. Their studies explored the influence of those teachers' efforts, along with how students' sense of place and their educational upbringing are related to the educators' perceptions entering 
the rural school. The challenges they delineated correspond with the struggles I experienced trying to incorporate my family into a rural community.

"Outsider" status in an Appalachian community is broadly defined. As expected, it describes one who is not originally from the community, but that status is also applied to former insiders who choose to leave the community. If and when they should return, they are no longer wholly "in" (Vance 2016). Vance asserted this reality from the perspective of the "insider", "And what was most important was to push them [outsiders] out as quickly as possible" (Gross 2016). Fisher \& Smith (2012) quoted Appalachian natives as believing that outsiders with agendas move in to take over the land and all of its many resources. This local sentiment seems to be reinforced by negative stereotypes of Appalachian people in popular culture combined with persistent corporate oppression of local communities. The unfortunate outcome of this perpetual cataloguing of locals as hillbillies has fed the local narrative that insiders are "good" and outsiders are "bad" (Fisher \& Smith 2012, 270). The history of the region as a political ground for personal advancement at the expense of exploiting the local population has formed long-lasting and perpetuating memories of skepticism toward anyone from the outside who comes offering something new. Generations of locals have seen outsiders come and go, each with their own agendas, none staying for long and all trying to change a way of life.

Another obstacle I confronted as an outsider was the idea of an arts organization as a nonprofit, rather than a business I was running that would line my own pockets. There were several locally operated nonprofit organizations that were successful in the community. They provided supplemental funds for families with cancer diagnoses, education and job training for single mothers, food and clothing for low-income families, and other social services. BAFA is an arts organization, and as such, does not provide for humanitarian needs. This difference in the nature of BAFA's mission caused many people locally to perceive BAFA as a business, rather than a nonprofit organization. On one occasion, following a successful performance weekend, the following was posted to a locally popular online message board.

"Did you see how much money she made during that show? BAFA is NOT a charity" (anonymous user post from Burkesville Topix, November, 2013).

This comment did not take into account the reality that $\mathrm{I}$, the executive director, was a volunteer, receiving no compensation for my services. Nor did it recognize that the funds from ticket sales from that show would 
provide the money to purchase costumes and build sets for the next production. The pervasive belief among many was that I owned BAFA and the building in which BAFA operated. I wonder if this perception has more to do with the arts as a foreign entity or if it is a manifestation of their mistrust of me, individually. Is it a return to the suspicion that I was an outsider interested only in exploiting the locality?

To confront this specific misconception, my board of directors had to become very active and highly visible. When it became apparent to us that some local people perceived me (and BAFA) in this way, we tried to head off the misinformation as quickly as possible. We began to promote the transparency of our financials and write pieces for the newspaper educating people about the nature of theatrical productions. One article, Why Do Theatre Tickets Cost So Much? ran in the local paper and gave a sample budget for a musical production, including performance rights from the publisher, costumes, sets, playbills and other advertising, etc. After that article ran in the newspaper I had people stopping me in the grocery store complimenting me on my ability to stretch a dollar. It was an amazing transformation in perception. This might seem like an easy victory, correcting a misunderstanding with correct information. The challenge was that corrections of perception did not seem to accumulate. When one bit of misinformation was clarified, something else stepped in to take its place. Again I return to my connection between the perception of the arts and my status as an outsider. They did not immediately understand what BAFA was trying to do, but perhaps they also didn't completely trust me to be the one to accomplish it.

We also felt our outsider status acutely where our children were concerned. My oldest was an infant when we moved to Burkesville and my youngest was born there, yet they too, were outsiders. It was evident when invitations were issued for birthday parties, and none of the native locals would attend. It happened reciprocally as well, as the only party invitations my children received were from other transplanted families. People were friendly and kind, would talk about how much their children loved my children, and yet the idea of socializing with us was taboo. My children seemed to be slowly overcoming this barrier in our final year in the community. As my oldest son progressed in athletic activities he began to be more accepted by some, but not all, of the parents. It leads me to believe that, had we stayed, eventually, he might have achieved a sort of alternative insider status. How much longer would this have taken? I have no idea. I also know, that in that process of trying to be accepted, he lost something of himself. He denied his enjoyment of the arts publicly, only participating privately. He discouraged his little brother from singing in 
the school talent show and was afraid to watch on the day of the performance, sure his brother would be mocked because, "Boys around here don't do that!" When my younger son sang, he was well-received, however, for his older brother, the threat was very real, and his precarious acceptance into the insider group was fragile.

As I attempt to understand the social environment $I$ faced in Cumberland County, one fact stands out as relevant. Cumberland County, Kentucky is one of only seven contiguous counties in south central Kentucky (along with Russell, Casey, Adair, Metcalf, Monroe, Clinton, and Wayne counties) that never had railroad service. No other comparably sized area of Kentucky remained untouched by the growth and development of this mode of transportation (Wooten 1992). Railroad companies found ways to reach the most remote and rugged places, even most of eastern Kentucky's deep Appalachian mountain regions. The arrival of the railroad in any Kentucky town marked the single most significant event shaping that town following the Civil War (Wooten 1992). Railroads facilitated the movement of people, goods, commerce, and ideas, and so, ushered in radical changes to the capital, social fabric, and landscapes of the communities they connected. The railroad placed any Kentucky town within a day's travel of major urban centers in the United States. Most of the state's county seats campaigned actively to bring railways into their communities (Wells 1947). Cumberland County, at the very center of that seven county area, sits the furthest of any Kentucky county from that bygone transportation revolution. It is worth noting that Cumberland County actively fought against the railroad's entrance into their community, twice voting down offers from rail carriers who would have expanded into Burkesville (Wells 1947). While other Kentucky counties were wooing and incentivizing railways to enter their communities, Cumberland County was actively opposing them. The absence of the railroad in Cumberland County is significant as we try to interpret the deficiency of arts activities and enrichment, as well. The revolutionary changes that occurred in much of Kentucky's Appalachian region have been more evolutionary in Cumberland County and the surrounding counties (Wooten 1992).

While art-rich institutions such as Berea College and Appalachian State were being founded in the latter half of the $19^{\text {th }}$ Century, the citizens of Cumberland County were actively fighting against the transportation revolution that would have connected them to other parts of the state. This connectedness among other Appalachian communities led to folk art making and sharing and cultivating among these other communities and Cumberland County was self-excluded from that sharing (Wooten 1992). 
This singular event of rejecting the railways created a pocket of isolation among these seven counties that makes them unique among the rest of Kentucky (Wells 1942).

Throughout my time in the community, I had to confront my own upper middle class upbringing. I was raised in an extremely ethnically and racially diverse community, but in that strategically planned community of tolerance, no one was poor. Thrust into a rural Appalachian community where I would already have been an outsider, I was more so because of my East Coast, upper middle class presentation. Sometimes I realized this and tried to account for it, changing the way I worded something to be more locally understood or modifying the way I dressed. I cannot claim that I ever fully overcame my own preconceptions but I tried. In this community, where all students go to one elementary school and then feed into one middle school, finishing at one high school, there are no divisions between the students from the wealthy neighborhood and those from the multi-family, government subsidized housing. This was a fully new concept to me, and I found it glorious. It didn't matter what your house looked like, you were all in the same classroom or on the same athletic team. In this way, I cannot deny that BAFA benefitted from the socioeconomic mixing that is so common in the community. We welcomed everyone, and many came. It opened my eyes to differences that I had been ignorant of in my own childhood. I valued the lesson and regularly tried to confront my innate biases, forcing myself to think through each assumption on merit. In this way, being treated as an outsider by the local residents made me stronger. It forced me to acknowledge the ways I considered myself an outsider, by admitting the ways I held myself apart as distinctly different.

I also realized that perhaps it was easier for me to be open with others who look different from me, because I somehow expect them to be different and, therefore, approach forming relationships with tolerance and openness and generosity for mistakes made by every party navigating difference. In Kentucky, the majority of people looked like me. I wonder if the shock of them being different was the source of much of my own confusion. I expected them to be like me and they were not. They expected me to be different, and I was. If I had approached them with the same openness that I approach people from other nations and races, perhaps I could have sooner earned their confidence. It was a hard lesson and it is uncomfortable revealing it now because I know that it reflects my own bias, however, I cannot change what I do not first acknowledge.

While we originally moved to Burkesville with the belief that we would raise our family there and stay, nine years later we moved for me to 
pursue my doctoral studies. Ultimately, we felt the environment lacking too many opportunities for our family as a whole. I toss this around in my mind. Did they win, kicking out the outsiders once and for all? Did I prove their suspicions right all along, moving in, causing a great change and then leaving? I know my intentions. I moved there to live, truly thinking I was there to stay. I hoped to make friends and establish my own roots. This is one of my greatest questions and perhaps even regrets. If I solidified in anyone's mind the idea that outsiders don't stick around, that brings me great sadness. As much as I highlight the negative experiences from my time there, Burkesville was my home. I might not have been accepted by the parents, but I was loved by and truly loved their children. My time there was well spent.

In fact, when I consider our slow acceptance into the society I have to acknowledge that it was through the children participating in BAFA that we finally became accepted outsiders. The children embraced us and were excited about what they learned through dance, music, theatre, and visual arts opportunities at BAFA. They insisted that their parents coordinate family vacations around BAFA opportunities so that they would not miss their favorite arts offerings. The children embraced BAFA, and by extension, me. They let me in.

At a board meeting for BAFA, to find a replacement for me as executive director, I offered the name of a qualified candidate living in a neighboring town. She is originally from Colorado but had been in Kentucky for several years.

"What about Lacy?" I offered.

"No, Elise, Burkesville won't accept her" came the immediate reply from a board member.

"But they know her, she's worked with BAFA before. They love her and she's qualified."

"But she's not from here, Elise" answered a different board member.

"I'm not from here, either" I reminded the women at the table.

"No, but you're different..."

"You're magical or something."

"You get away with it..." Three replies from three people overlapping one another.

"Wait," I was stunned. "I am not from here either. They hardly accept me at all."

"No, you're not one of us, but we've sort of adopted you. You're awfully nice to have around!" The group of women around me all laugh with me, recognizing the seeming absurdity of the quasi-compliment they just bestowed upon me. It took my nine years and an unknowable number 
of hours investing in the youth in the community, but I had ascended. I was adopted.

\section{Perception of the Arts}

It was the fourth day of a five-day fine arts summer camp in Burkesville, Kentucky. A big, burly man, complete with the stereotypical beard and flannel shirt, grabbed me and embraced me fiercely. With tears in his eyes he whispered, "Thank you for giving my daughter back to me." He then explained that the previous year she had been bullied and had become reclusive and taciturn. Since beginning our program four days prior I had watched this child shine and smile, laugh and engage. I would never have known of her previous struggles. I asked her father why our organization had made such a difference. He replied, "You see her, and you helped her see herself."

Based on the previous anecdote, imagine my surprise when the above mentioned student came up to me with tears in her eyes and told me that she would not be able to participate in BAFA's fall activities because her parents would not let her quit the basketball team. She expressed her preference for BAFA as an extracurricular activity, but explained that her parents simply didn't think it would have a lasting impact. She was twelve years old.

In the rural, isolated communities of Appalachia, the arts are perceived as the province of the young. Dawes and Larson (2011) found that students are motivated to continue arts involvement only through deep emotional investment in the activity. If they do not engage psychologically, they will not persist in the program long-term. I found this to be true of my own program, but I further faced the challenge of parental authorities and peer groups steering students away from artistic endeavors. Students who were heavily engaged at BAFA would have to step away from arts activities for the duration of a particular athletic season. The students did not desire to do so, but parental and peer influences demanded it. Kraehe and Acuff (2013) confronted the issue of underservedness and confirmed that low participation is largely influenced by lack of previous exposure. The students who have the greatest needs are often in the districts with the fewest resources for arts activities. Turner (2012) concurred that it is social class, more than any other designation, that provides the filter for what activities will or will not be endorsed. As a systemic and generational reality, this has created a culture of ignorance with regard to artistic achievement and enrichment. In his 2016 study, Skippington found that few community members and 
businesses in the rural communities he studied perceived the arts to play any role of importance in community life and development.

There were many other perception challenges as I attempted to explain the nature of Burkesville Academy of Fine Arts Summer Camp, the first year we were enrolling. That first year we offered classes in painting, drawing, sculpture, ballet, tap, jazz, hip hop, interpretive, musical theatre, drama basics, improvisation, piano, guitar, chorus stage makeup and stage fighting. In a community that had not experienced the fine arts, most of these classes were foreign in both name and course content. One conversation with a potential student's father gives a perfect illustration of the nature of conversations I had as my program was just beginning. $\mathrm{He}$ called to ask what classes we had available for his son who loved to draw. I mentioned that, beyond the obvious art content, his son might really enjoy stage makeup, because of the artistic applications included in the class. "You're not teaching my son anything about makeup" was his first response. When I tried to clarify the nature of the class he responded "I'm not gonna pay you to teach my son face paintin'" (personal correspondence, May 2012). I tried to assure him that what we were offering was neither a makeup class nor a face painting class, but rather, the introduction of highly intricate, artistic applications of Broadway quality stage makeup to create and design unique and original characters. "Yeah, I don't think he's gonna need to learn all that," came the reply.

I quickly learned when to provide more information for clarification and when to just let the misunderstanding go without explanation. Sometimes, trying to clarify led to even greater confusion. It felt like when I am trying to define a big word for my small sons and can only think of other big words as synonyms. One of the biggest obstacles I faced was the broad misperception of what the fine arts really are, and why they are valuable. There is some understanding of music, especially bluegrass, as a valid pastime, and there are visual artists who practice folk-arts such as wood or clay sculpture or quilting, but the performing arts, including theatre and dance were an enigma locally.

There are few studies of the actual impact of the introduction of arts onto local populations but one that is relevant is Bolton (1969). Her account of teaching art to underserved, rural students described one portion of the perception problem, and that is the previous lack of exposure. In her study, she found that some children had not even been exposed to simple artistic mediums common to American childhood, crayons, coloring books and the like were unknown to the students she surveyed. Broome (2016) discussed a similar phenomenon when dealing with migrant populations. While not rural Appalachian students, the 
reality of lack of prior exposure creates critical obstacles for some students when trying to affect their perceptions of what is and is not art. Moreover, when the problem of underexposure is generational, the parents of these students place little to no value on the arts as enrichment activities. After all, if what they had, or didn't have, as children was good enough for them, it is good enough now, as well (DeYoung 1993). In addition, DeYoung (1995) explored how rural school administrators deliberately teach and model what they perceive to be normative behavior. What was normal and familiar to them is perpetuated as normative for their students.

In King's (2012) analysis she credited not the unfamiliarity of the activity itself but rather the perceived necessity of it. In her estimation, the acceptance or rejection of activities is based on whether it is deemed necessary for survival. Those living in, what she terms, a state of 'lacks" will choose their leisure based on what will ultimately provide the greatest end reward for investment. In the case of the arts in Burkesville, this is worth exploring. My perception is that athletics were encouraged because of the possibility of scholarships earned if a student excelled. The arts were a foreign entity and unknown as a provider of any such future benefit. The reader might ask, "But what about music, theatre, dance, or visual arts scholarships?" This brings us to another challenge. Rather than leaving for college, many students may be pressured to choose family cohesiveness and remain in the area (Corbett as cited by Hendrickson 2012). In the case of Cumberland County Kentucky, there were regionally local colleges and universities with athletic opportunities but arts programs were limited within the preferred local institutions of higher learning. The first two seniors to graduate from the BAFA program who sought degrees in the arts both received full scholarships, one in vocal performance and one in theatre. However, those students were willing to travel farther from home for their college education than many in the community were comfortable doing.

I don't have a tidy story to tell on this subject, only a series of encounters, like the one above, that made it clear to me that I could never assume that others completely understood what I was talking about when I was discussing the arts. Sitting around a large table, covered in old paint smudges, surrounded by left-behind child-art treasures adorning the walls the BAFA board of directors sat to discuss possible programming options and fundraising events. I opened the question up to the board of directors, "What do you all think we should offer?"

"I just still don't think people understand what we do here" came the reply of one member. She continued, "I've been asked if BAFA does Princess events, or if we teach gymnastics." Through side chuckles, 
another board member chimed in, "Uh I think I get that question a few times every week...does BAFA do tumbling classes" (Board minutes, August 2014).

Feeling deflated I added my voice. "I don't understand that. We keep promoting the mission statement. We advertise our dance, music and arts classes. We do theatrical productions... why is it still so ambiguous? I am wide open to your feedback...I know I'm the newbie here!” After more chuckles and some polite smiles one member looked at me and responded, "This is that new, Elise. Putting on a costume to play Hamlet is the same here as putting on a costume to be a princess at a birthday party. You can't fix that overnight. I think we're doing great, but that is just going to take time..." After a long, silent pause another voice speaks, "a long, l.o..n..g time!" Laughter surrounded the table and filled the room. This disconnect between what we offered and what many people thought we might offer persisted, but it did improve with time.

The University of Kentucky Cooperative Extension Program serves as a link between the university and the 120 counties of the Commonwealth. Its mission is to improve the lives of community members through educational programming. The Extension office organizes the 120 counties into seven districts, each with a supervisor and with program coordinators who work with the various divisions. Three of these counties also offer Fine Arts programs. Unfortunately, none of those counties are in the region surrounding Burkesville (Maschio 2016). Brown \& Swanson (2013) explored the perceptions of the arts in rural Kentucky and found that projects operated by the Cooperative Extension Service are accepted and embraced because the rural citizenry is comfortable with engaging in Extension programs, having been familiarized with the organization for decades through agricultural programs. In communities where the Extension Service operates fine arts programming, it is often well received.

This proved true in Burkesville, Kentucky, as well. When BAFA began to partner with the Extension Service we had a broader range of participants than when we operated independently. The personal identification as members of the local community further reinforces the programs that individuals are willing to utilize (Cooper, Knotts, and Livingston 2010). If the individual or family identify as natives of the community they are less willing to buy into new activities. This resistance even permeates established activities with local significance (team sports, 4-H, boy scouts, and other common activities) if they operated by outsiders, rather than native locals (Vance 2016). Regarding activities perceived as "other," Grimes, Haskins, and Paisley $(2013,44)$ had this to 
say, "It's not that far geographically, if you think about it, but [the city] is like another world to them".

Another perception obstacle I confronted was the idea of an arts organization as a nonprofit. There were several locally operated nonprofit organizations that were successful in the community. They provided supplemental funds for families with cancer diagnosis, education and job training for single mothers, food and clothing for low-income families, and other social services. BAFA is an arts organization, and as such, does not provide for humanitarian needs. This difference in the nature of BAFA's mission caused many people locally to perceive BAFA as a business, rather than a nonprofit organization. On one occasion, following a successful performance weekend, the following was posted to a locally popular online message board.

"Did you see how much money she made during that show? BAFA is NOT a charity" (anonymous user post from Burkesville Topix, November, 2013)!

This comment did not take into account the reality that I, the executive director, was a volunteer, receiving no compensation for my services. Nor did it recognize that the funds raised from ticket sales from that show would provide the money to purchase costumes and build sets for the next production. The pervasive belief among many was that I owned BAFA and the building in which BAFA operated. I wonder if this perception has more to do with the arts or if it is a manifestation of their mistrust of me, individually. Is it a return to the suspicion that I was an outsider interested only in exploiting the locality? I don't know. I might never know, but maybe future research will be able to dissect these two issues from one another to better facilitate interactions between Appalachian communities, outsiders and arts activities.

To confront this specific misconception, my board of directors had to become very active and highly visible. When it became apparent to us that some local people perceived me (and BAFA) in this way, we tried to head off the misinformation as quickly as possible. We began to promote the transparency of our financials and write pieces for the newspaper educating people about the nature of theatrical productions. One article, Why Do Theatre Tickets Cost So Much? ran in the local paper and gave a sample budget for a musical production, including performance rights from the publisher, costumes, sets, playbills and other advertising, etc. After that article ran in the newspaper I had people stopping me in the grocery store complimenting me on my ability to stretch a dollar. It was an amazing transformation in perception. This might seem like an easy victory, correcting a misunderstanding with correct information. The 
challenge was that corrections of perception did not seem to accumulate. When one bit of misinformation was clarified, something else stepped in to take its place. Again I return to my connection between the perception of the arts and my status as an outsider. They did not immediately understand what BAFA was trying to do, bringing inter-disciplinary arts education to the children of the community, but perhaps they also didn't completely trust me to be the one to accomplish it.

Kahn (2012) examined the distrust local Appalachians feel toward outsiders as interlopers. The history of the region as a political ground for personal advancement at the expense of exploiting the local population has formed long-lasting and perpetuating memories of skepticism toward anyone from the outside who comes offering something new. Generations of locals have seen outsiders come and go, each with their own agendas, none staying for long and all trying to change a way of life (Kahn 2012).

One contrary perception of the potential for art in Appalachia is expressed in Mullinax (2012), that is, the arts as instigator of social change. Community-based art has a history of impact in the poor regions of Appalachia. This movement did not stretch so far as Cumberland County, where I was located. Burkesville was just too far West to be considered "true" Appalachia but just a bit too far East to be free of its influences and attitudes.

Again, I must return to the influence of young people. I think the greatest reason we were able to change people's perceptions and expectations about the arts offered by BAFA, is that children made it relevant. Parents try to care about what their children care about and as we became more influential in children's lives, they made sure their parents knew it. Who can say what the arts expectations in Burkesville will be in twenty years, as BAFA continues providing inter-disciplinary arts education?

\section{Method}

As a method, autoethnography combines aspects of autobiography and ethnography. In autobiography, the author selectively reflects on past events and experiences. There is usually not a predetermination that the author will write the autobiography, rather, the events are compiled using the guide of hindsight. Ethnography, on the other hand, is a deliberate act of research, wherein the researchers study and observe a culture's practices, values, beliefs and more to facilitate greater understanding of the culture by both insiders and outsiders. Ethnographers accomplish this by becoming participant observers, taking field notes of their engagement within the culture being studied (Ellis 2004). 
For the researcher doing autoethnography, (she retrospectively and selectively writes about cultural experiences and analyzes these events to place them in the context of other scholarly research. The end goal is to produce an aesthetic and evocative detailed description of the culture through descriptions of lived-experiences. Autoethnographers subscribe to the belief that research can be simultaneously rigorous, theoretical and analytical while also being emotionally evocative and inclusive of social experiences. This requires the researcher to be vulnerable and acknowledge inherent biases and prejudice as she reflects on her time within the community being researched (Ellis, Adams, \& Bochner 2010).

My personal autoethnography of the founding of BAFA included field notes in the form of my personal journals, written over the course of nine years living as a resident of Burkesville, Kentucky. Additionally, I utilized newspaper articles and reviews of the activities engaged in by BAFA during my time as founder and executive director. These journals and newspaper documents were supplemented by letters from and interviews with parents and student participants in the program.

I chose autoethnography as my method for this project because these experiences occurred prior to my time as a researcher and yet I see extensive research potential in nearly every aspect of my time in that community. I did not relocate to Kentucky as a researcher, planning to interview, study and depart. Rather, I moved there, bought a home and settled in with the intention of raising my family as part of the community. This affected my behavior in profound ways, for example, encouraging me to try to blend in and form relationships sincerely and intimately. This would not have occurred if I had entered the town thinking I was there to study only. These authentic experiences of my efforts to assimilate myself and my family into Burkesville, combined with my unique endeavor of establishing an arts organization on Main Street, provide a ground rich with opportunities for examination and exploration. In addition, because I live a lifestyle of journaling, I have an extensive catalogue of the circumstances, conversations and my own emotions throughout my time in this community. These journal entries are untainted by my current potential biases as I attempt to interpret past events. They were written in the midst of the journey and, therefore, any biases they might communicate were also part of the experience and worth uncovering.

\section{Conclusion}

There is substantial literature available for me to interpret my experiences as an outsider in the Appalachian region (Azano \& Stewart 2015 \& 2016; Vance 2016; Fisher \& Smith 2012; Kahn 2012; Grimes, Haskins and 
Paisley 2013; Brown \& Swanson 2013). Published works reinforce that my experiences are normative for one entering into those communities. Outsider status is real but can best be compensated for through relationship building. True insider status might never be achieved but this outsider-author was able to become a trusted "adopted other."

The perception of the arts is a harder topic to study, although research demonstrating the rejection of new ideas and programs seems to support my lived experience as I attempted to establish an arts education organization in a previously underserved population. In addition, the unique isolation of Cumberland County provides insight into the particulars of my experience introducing new programs. Perception of the arts can best be improved through continued exposure of the local population to arts activities. Incorporating "insider" citizens into the program activities and partnering with trusted, established organizations were successful strategies employed at BAFA. The author was surprised to discover the entwining of outsider status and arts perception as similar and entangled obstacles. Further research might better separate these two phenomena into more distinguishable occurrences.

Throughout my time in Burkesville, I regularly questioned myself, my motives, my qualifications and capabilities. These are not doubts that had plagued me prior to living in that community. I wondered why, for the first time in my life, I was unable to make friends. Working on this autoethnography comforted me by enlightening me to the reality of outsider status as a real, researched, documented phenomena. Knowing that I was not alone made the sting of rejection much less potent. On the other hand, learning about the history and motivations behind the rejection of outsiders forced me to confront my own prejudices and preconceptions. I did move into the community thinking I might have something to offer. I placed myself above, because I had experiences and education that the locals did not. It is humbling to realize my own biases. Perhaps they did not trust me at first because I did not show that I deserved that confidence.

Bringing the arts into rural, especially isolated, communities is not so simple as just offering a class or opening a facility. If my experiences in Burkesville, Kentucky mean anything more broadly applicable, it is that relationship is necessary first. I would never, no matter how long I stayed, have crossed the threshold and become accepted as an insider, but because I was working with children and this was perceived to be positive, I was able to achieve the status of "adopted other". This enabled me to establish trust and, despite the other obstacle of perception, ultimately made my work in the community successful and lasting. There are many factors that make Cumberland County Kentucky a unique geographical and social 
case study, however, I believe the ultimate lesson, that researchers must establish relationships of reciprocity before observing or impacting rural, isolated communities could be broadly applicable. More study in this regard could benefit rural communities, as well as other underserved or underexposed populations in the arts.

\section{References}

Appalachian State (n.d.) Retrieved from http://www.appstate.edu/about/

Azano, Amy Price and Stewart, Trevor Thomas. 2015. "Exploring Place And Practicing Justice: Preparing Pre-Service Teachers For Success In Rural Schools." Journal of Research in Rural Education 30 (9): 1-12.

Azano, Amy Price and Stewart, Trevor Thomas. 2016. "Confronting Challenges At The Intersection Of Rurality, Place, And Teacher Preparation: Improving Efforts In Teacher Education To Staff Rural Schools." Global Education Review 3 (1): 108-128.

Barrett, Savannah Chantal. 2013. "The Community Arts Programs Of The Cooperative Extension Service: Comparative Study Of Arts Initiatives In Kentucky And Wisconsin." Retrieved from http://scholarsbank.uoregon.edu/xmlui/handle/1794/12924.

Bolton, Shirley L. 1969. "An Introductory Study Of Art As Creative Learning For The Rural Culturally Disadvantaged." Studies In Art Education 2: 50-56. doi:10.2307/1319612

Brown, David L., and Louise E. Swanson. 2003. Challenges for Rural America in the Twenty-First Century. Rural Studies Series. University Park: Pennsylvania State University Press. Retrieved from http://www.loc.gov/catdir/toc/ecip043/2003009910.html.

Berea College. (n.d.). Retrieved from https://www.berea.edu/about/

Broome, Jeff. 2016. “Art Education With Migrant Hispanic Populations In Multi-Age Elementary Classrooms: Instructional Strategies Learned From Practice." In Culturally Sensitive Art Education in a Global World, edited by Marjorie Cohee Manifold, Steve Willis, \& Enid Zimmerman, 181-189. Alexandria, VA: National Art of Education Association. 
Cooper, Christopher, Gibbs Knotts, and Don Livingston. 2010.

"Appalachian Identity And Policy Opinions." Journal of Appalachian Studies 1/2 (26).

Dawes, Nickki Pearce \& Reed Larson. 2011. "How Youth Get Engaged: Grounded-Theory Research On Motivational Development In Organized Youth Programs.” Developmental Psychology (1): 259.

DeYoung, Alan J., \& American Institutes for Research in the Behavioral Sciences, P. C. 1993. "Children At Risk In America's Rural Schools: Economic And Cultural Dimensions." Retrieved from http://www.eric.ed.gov/contentdelivery/servlet/ERICServlet?accno $=\mathrm{ED} 362339$.

DeYoung, Alan J. 1995. "Constructing And Staffing The Cultural Bridge: The School As Change Agent In Rural Appalachia.” Anthropology \& Education Quarterly (2): 168.

Ellis, Carolyn. 2004. The Ethnographic I: A Methodological Novel About Autoethnography. Walnut Creek, CA: AltaMira.

Ellis, Carolyn, Tony E. Adams, and Arthur P. Bochner. 2010.“Autoethnography: An Overview." Forum Qualitative Sozialforschung / Forum: Qualitative Social Research. 12 (1). Retrieved from http://www.qualitativeresearch.net/index.php/fqs/article/view/1589.

Fisher, Stephen L. and Barbara Ellen Smith. 2012. Transforming Places: Lessons From Appalachia. Chicago, IL: University of Illinois Press.

Grimes, Lee Edmondson, Natoya Haskins, and Pamela O. Paisley. 2013. "So I Went Out There: A Phenomenological Study On The Experiences Of Rural School Counselor Social Justice Advocates." Professional School Counseling 1 (40).

Gross Terry. 2016. Interview of J. D. Vance. Fresh Air [Radio broadcast]. Philadelphia: Public Radio. (2016, August 17). 
Hendrickson, Katie A. 2012. "Student Resistance To Schooling:

Disconnections With Education In Rural Appalachia." The High School Journal 95 (4): 37-49.

Kahn, Si. 2012. "Organizing, Culture, And Resistance In Appalachia:

Past, Present, And Future." Journal of Appalachian Studies (1/2): 8.

Kieffer, Elise Lael. 2013. "Why Do Theatre Tickets Cost So Much." Cumberland County News, February 3.

King, Cheryl Simrell. 2013. "What's A Girl Like You Doing In A Place Like This?" Journal of Public Affairs, Education 18 (1): 51-66.

Kraehe, Ameila M., \& Joni B. Acuff. 2013. "Theoretical Considerations For Art Education Research With And About 'Underserved Populations"”. Studies in Art Education 54 (4): 294-309.

Maschio, Geraldine. 2016. "Making, Keeping, And Revitalizing The Arts In Appalachia." The Journal of Art for Life 8 (6): 1-15.

Mullinax, M. 2012. "It's About Being A Resident Of A Place: A Case Study Of Practicing Civic Engagement Through Community -Based Art And Oral History I Harlan County, Kentucky." (Doctoral dissertation). Retrieved from https://searchproquestcom.proxy. lib.fsu.edu/docview/1506674843/fulltextPDF/969BDC73D6E40B $4 \mathrm{PQ} / 4$ ?accountid $=$ 4840. $(3579386)$.

National Register of Historic Places. The Coe House, Cumberland County, Kentucky, National Register \#Asset ID 09001138.

Skippington, Peter. 2016. Harnessing The Bohemian: Artists As Innovation Partners In Rural And Remote Communities. Canbera, Australia: ANU Press.

Turner, William H. 2012. "Reactions To 'Organizing, Culture, And Resistance In Appalachia: Past, Present, And Future': Si Kahn Sings To A Harlan County Choirboy." Journal of Appalachian Studies (1/2): 25. 
Vance, J. D. 2016. Hillbilly Elegy: A Memoir Of A Family And Culture In Crisis. New York, NY: Harper, an imprint of Harper Collins Publishers.

Wells, J. W. 1947. History of Cumberland County. Louisville, KY: Standard Printing Company.

Wooten, Ruth. 1992. Cumberland County, Kentucky, Yesterday And Today. Dallas, TX: Curtis Media Corporation. 